\title{
Interpretation of low birth weight babies by anthropometric measurements in South India
}

\author{
Doddamani R. ${ }^{1}$, Jyothi S.D. ${ }^{2}$, Pujar T.V. ${ }^{3}$ \\ ${ }^{1}$ Dr. Raghavendra Doddamani, Assistant Professor, Department of Pediatrics, JJMMC, Davangere, ${ }^{2}$ Dr. Jyothi S.D., \\ Assistant Professor, Department of Pediatrics, Belgaum Institute of Medical Sciences, Belgaum, ${ }^{3}$ Dr. Tejaswi Vittal \\ Pujar, Associate Professor, Department of Obstetrics and Gynecology, SSIMSRC, Davangere, Karnataka, India.
}

Corresponding Author: Dr. Jyothi S.D., Assistant Professor, Department of Pediatrics, Belgaum Institute of Medical Sciences, Belgaum. E-Mail id: rags_md@yahoo.co.in,drjyothipgbelgaum@gmail.com

\begin{abstract}
Introduction: Low birth weight is seen most commonly in developing countries. In India majority of births are conducted at home by the Traditional Birth Attendants (TBA) or relatives, where the estimation of birth weight is not done because of lack of weighing machines. Therefore, an early identification and prompt referral of LBW newborns is vital in preventing neonatal deaths. Objective: To determine the magnitude of low birth weight babies and to correlate birth weight and other anthropometric measurements. Methodology: This is a cross sectional study done at Christian fellowship hospital, Oddanchatram, Dindigal, Tamilnadu from $1^{\text {st }}$ Dec 2011 to $31^{\text {st }}$ Nov 2012. 500 newborns were examined within 24 hours of their birth in this hospital during this period. Antenatal history and anthropometric measurements were recorded. Results: The male newborn $(57.2 \%)$ were more than of female $(42.8 \%)$. The magnitude of the low birth weight was $262(52.4 \%)$. It was observed that correlation coefficients of all the parameters are positive and are statistically significant $(\mathrm{p}<0.001)$. Maximum and minimum positive correlation was observed in case of thigh circumference $(r=0.776)$ and Foot length $(r=0.460)$ respectively.
\end{abstract}

Keywords: Anthropometric measurements, Correlation, Low birth weight, Thigh circumference

\section{Introduction}

World Health Organization defines Low Birth Weight (LBW) as baby weight at birth less than 2,500 grams. Globally, LBW is a considerable public health problem which is associated with consequences that have effects for both short-and long term. On estimation, 15-20\% of all births worldwide are low birth weight, representing more than 20 million births a year. With great variation in the prevalence of LBW across the countries, it is seen more in developing than developed countries; especially in the most vulnerable populations.

Regional estimates of low birth weight include $28 \%$ in south Asia, 13\% in sub-Saharan Africa and 9\% in Latin America [1, 2]. In 2011, Indian Statistical Institute reported nearly $20 \%$ of new born have LBW in India [3]. Low birthweight is associated with foetal and neonatal mortality and morbidity, inhibited growth and cognitive development, and chronic diseases later in

Manuscript received: $10^{\text {th }}$ July 2018

Reviewed: $20^{\text {th }}$ July 2018

Author Corrected: $27^{\text {th }}$ July 2018

Accepted for Publication: $31^{\text {st }}$ July 2018 life. In India, infant mortality rate remains unbearably high at 34 per 1000 live births. [4]. Recording of birth weight is universal in developed countries and in regions where deliveries are conducted in hospitals. But in developing countries like India majority of births are conducted at home by the Traditional Birth Attendants (TBA) or relatives, where the estimation of birth weight is not done because of lack of weighing machines.

Therefore, an early identification and prompt referral of LBW newborns is vital in preventing neonatal deaths. Due to limited resources, it is not possible to provide expensive weighing scales to the community members and families.

Therefore, it is essential to find out an alternative method for the estimation of birth weight. Hence, this study is done with the objective to find out the relationship between birth weight and different anthropometric measurements from which low birth weight babies could be identified reliably and managed accordingly. 


\section{Objectives}

1. To determine the magnitude of low birth weight babies.

2. To correlate birth weight and other anthropometric measurements.

\section{Methodology}

Study design: Cross sectional study

Study place: Christian fellowship hospital, Oddanchatram, Dindigal, Tamilnadu.

Study duration: $1^{\text {st }}$ Dec 2011 to $31^{\text {st }}$ Nov 2012 .

Study population: Live newborns of term gestation in Christian fellowship hospital, Oddanchatram, Dindigal, Tamilnadu.

Sample size: 500 (convenient sampling method)

Inclusion criteria: All live newborns of term gestation

\section{Exclusion criteria}

- Preterm babies

- Asphyxiated/ sick newborns under intensive care in the first 24 hours of birth.

Data Collection: Relevant antenatal history was obtained with interview of mother within 24 hours of child birth and through review of obstetric case sheets. Gestational age assessment was done by New Ballard Score as described by Ballard J.L. et al. [5]

\section{Anthropometric measurements}

The anthropometricmeasurements were recorded in the newborn in awarm environment.

- Birth weight of naked baby was measured with the spring scale to the nearest $25 \mathrm{~g}$.

- Head circumference (HC) was measured with a nonstretchable measuring tape placed over the occiput at the back and just above the supra-orbital ridges in front. The maximum occipito-frontal circumference was recorded to the nearest $0.1 \mathrm{~cm}$.
- Chest circumference (CC) was measured to the nearest $0.1 \mathrm{~cm}$ at the level of nipple/fourthcostosternal joint.

- Mid upper arm circumference (MUAC) was measured at the mid-point between the tip of acromion and the olecranon process in the left upper arm with the non-stretchable measuring tape to the nearest $0.1 \mathrm{~cm}$.

- Thigh circumference (TC) was measured in supine position to the nearest $0.1 \mathrm{~cm}$ at the level of the lowest gluteal furrow of left thigh, the tape being placed perpendicular to the long axis of the left lower limb.

- Calf circumference ( $\mathrm{Ca} \mathrm{C}$ ) was measured at the most prominent point in semi-flexed position of the leg with the measuring tape to the nearest $0.1 \mathrm{~cm}$.

- Foot length (FL): A $15 \mathrm{cms}$ long sliding gauge with divisions upto $0.05 \mathrm{~cm}$ was prepared. Heel was stabilised against the fixed vertical end of the gauge and sliding end was adjusted against the tip of big toe after straightening the foot and foot length measurement was recorded to the nearest $0.1 \mathrm{~cm}$.

- Crown-heel length (CHL) was recorded to the nearest of $0.1 \mathrm{~cm}$ on an infantometer with the baby being supine, knees fully extended and soles of feet held firmly against the foot board and head touching fixed board.

Statistical analysis- The data was entered into Microsoft excel sheet and analysed using SPSS Version 10 software.

The data will be represented in the form of descriptive statistics like frequency, percentages, mean, standard deviation.

Correlation Coefficient (r) of individual anthropometric measurements with respect to birth weight was calculated and the The statistical significance was evaluated at 95\% confidence level $(\mathrm{p}<0.05)$. Regression equations were drawn to predict birth weight based on other anthropometric measurements.

\section{Results}

The male new borns $(57.2 \%)$ were more than of female $(42.8 \%)$. The magnitude of the low birth weight was 262 $(52.4 \%)$. The details of the low birth weight with respect to sex are described in table 1 . 
Table-1: Distribution of low birth weight babies according to sex.

\begin{tabular}{|c|c|c|c|c|c|c|c|}
\hline & \multicolumn{2}{|c|}{ Male } & Female & \multicolumn{2}{c|}{ Total } \\
\hline LBW & Frequency & Percent & Frequency & Percent & Frequency & Percent \\
\hline \multicolumn{7}{|c|}{ Present $(\mathbf{n}=\mathbf{2 6 2 , 5 2 . 4 \% )}$} \\
\hline$<2$ & 6 & 2.10 & 10 & 4.70 & 16 & 4.2 \\
\hline $2.01-2.5$ & 142 & 49.70 & 104 & 48.60 & 246 & 49.2 \\
\hline \multicolumn{7}{|c|}{ Absent (n= 238, 47.4\%) } \\
\hline $3.51-3$ & 138 & 48.30 & 99 & 46.30 & 237 & 47.4 \\
\hline Total & 0 & 00 & 1 & 0.50 & 1 & 0.2 \\
\hline
\end{tabular}

The mean, standard deviation and correlation of the anthropometric measurements are described in table 2 and table 3.

Table-2: Anthropometric measurements of the study subjects

\begin{tabular}{|c|c|c|c|}
\hline Sl.No. & Anthropometric measurements & Mean & Std. Deviation \\
\hline 1 & Weight $(\mathrm{kg})$ & 2.58 & 0.676 \\
\hline 2 & Crown Heel length $(\mathrm{cm})$ & 46.45 & 3.460 \\
\hline 3 & Head circumference $(\mathrm{cm})$ & 32.74 & 1.724 \\
\hline 4 & Mid upper arm circumference $(\mathrm{cm})$ & 9.53 & 1.106 \\
\hline 5 & Thigh circumference $(\mathrm{cm})$ & 30.56 & 1.839 \\
\hline 6 & Chest circumference $(\mathrm{cm})$ & 7.45 & 0.658 \\
\hline 7 & Foot length $(\mathrm{cm})$ & 9.77 & 1.020 \\
\hline 8 & Calf circumference $(\mathrm{cm})$ & 340 \\
\hline
\end{tabular}

Table-3: Correlation matrix between anthropometric parameters

\begin{tabular}{|c|c|c|c|c|c|c|c|c|}
\hline $\begin{array}{c}\text { Correlation } \\
\text { co-efficient }\end{array}$ & Wt & CHL & HC & MUAC & TC & CC & FL & Ca C \\
\hline Wt & 1 & $.492^{*}$ & $.609^{*}$ & $.635^{*}$ & $.776^{*}$ & $.581^{*}$ & $.460^{*}$ & $.646^{*}$ \\
\hline CHL & & 1 & $.573^{*}$ & $.484^{*}$ & $.508^{*}$ & $.593^{*}$ & $.430^{*}$ & $.548^{*}$ \\
\hline HC & & & 1 & $.628^{*}$ & $.485^{*}$ & $.849^{*}$ & $.526^{*}$ & $.644^{*}$ \\
\hline MUAC & & & & 1 & $.577^{*}$ & $.671^{*}$ & $.614^{*}$ & $.790^{*}$ \\
\hline TC & & & & & 1 & $.571^{*}$ & $.347^{*}$ & $.662^{*}$ \\
\hline CC & & & & & & 1 & $.553^{*}$ & $.659^{*}$ \\
\hline FL & & & & & & & &. \\
\hline Ca C & & & & & & & & \\
\hline
\end{tabular}

*significant

From table 3, it was observed that correlation coefficients of all the parameters are positive and are statistically significant $(\mathrm{p}<0.001)$. Maximum and minimum positive correlation was observed in case of thigh circumference $(\mathrm{r}=$ $0.776)$ and Foot length $(r=0.460)$ respectively. 
Chart-1: Scatter plots between birth weight and other anthropometric measurements.
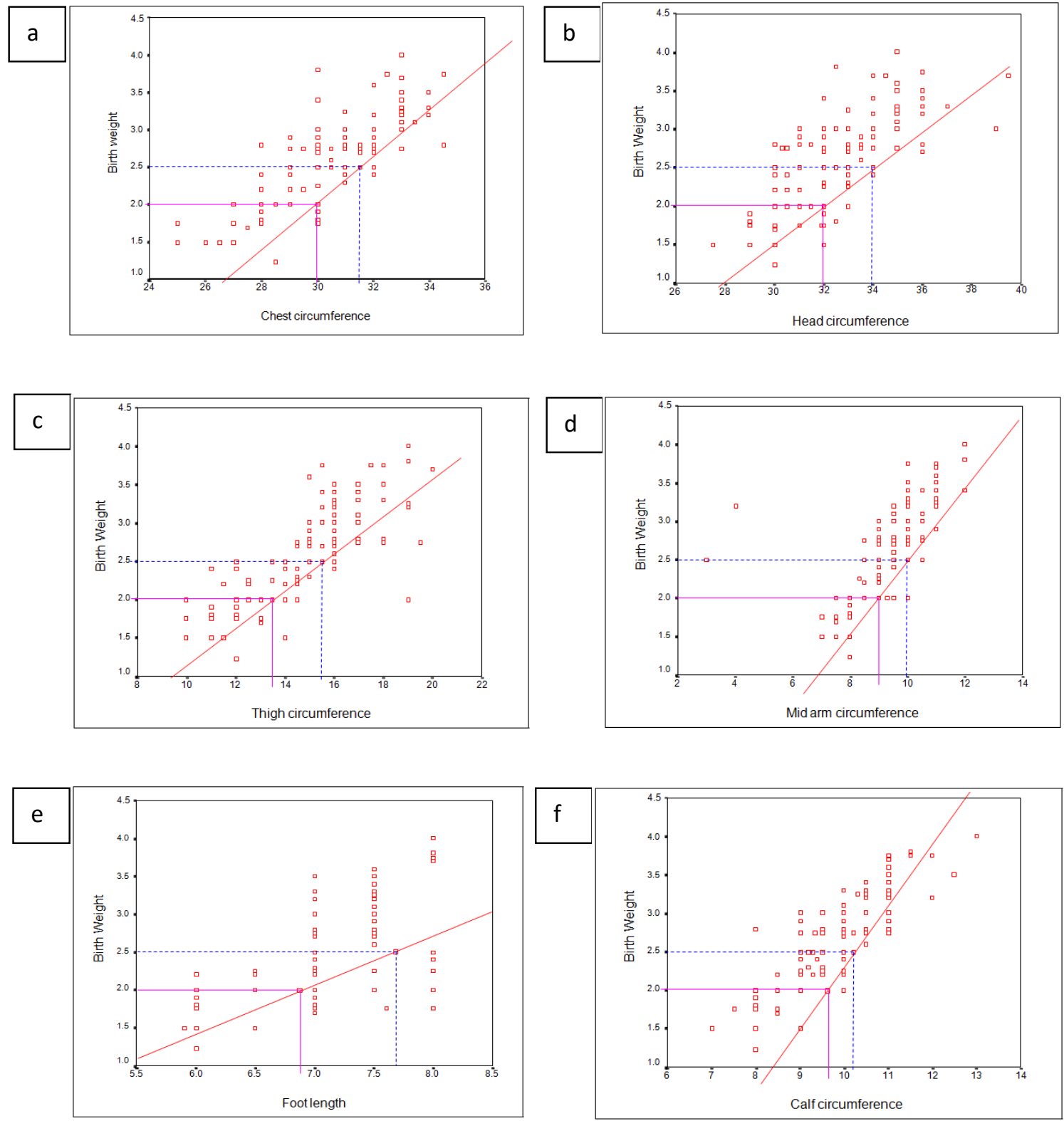

\section{g}

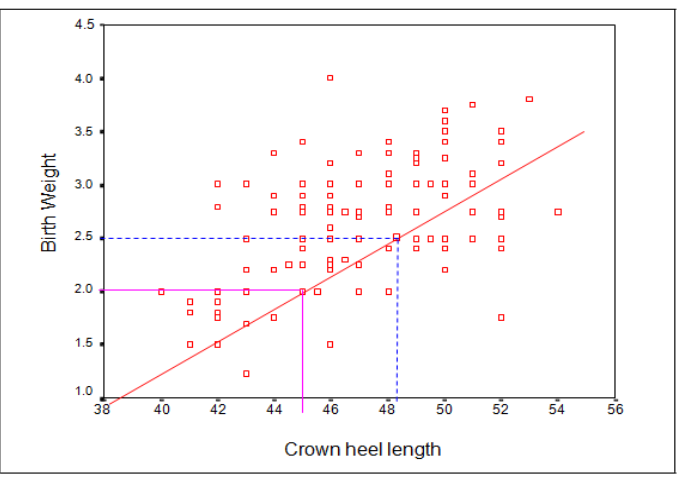

\section{Scatter plots between}

a. Birth weight and Head circumference

b. Birth weight and Chest circumference

c. Birth weight and MUAC

d. Birth weight and Thigh circumference

e. Birth weight and Calf circumference

f. Birth weight and Foot length

g. Birth weight and Crown heel length

Scatter plots are drawn between birth weight and other anthropometric measurements. (Chart 1). The cut off values and regression equation are described in table 4. 
Table- 4: Regression equations for anthropometric measurements.

\begin{tabular}{|c|c|c|}
\hline Anthropometric measurements & Regression equation & Cut off \\
\hline CHL & BW (in $\mathrm{kg})=-4.1427+0.1371 \times \mathrm{CHL}$ & 48.45 \\
\hline HC & BW (in $\mathrm{kg})=-6.4285+0.264 \times \mathrm{HC}$ & 33.82 \\
\hline MUAC & BW (in $\mathrm{kg})=-2.7467+0.5254 \times \mathrm{MUAC}$ & 9.99 \\
\hline TC & BW (in $\mathrm{kg})=-1.6672+0.2693 \times \mathrm{TC}$ & 15.47 \\
\hline CC & BW (in $\mathrm{kg})=-6.3497+0.2809 \times \mathrm{CC}$ & 31.50 \\
\hline FL & BW (in $\mathrm{kg})=-2.6910+2.5 \times \mathrm{FL}$ & 7.67 \\
\hline Ca C & BW (in $\mathrm{kg})=-3.0309+0.5397 \times \mathrm{CC}$ & 10.25 \\
\hline
\end{tabular}

\section{Discussion}

The early identification of low birth weight babies is an important pre-requisite of any initiative to reduce mortality. In many developing countries including India, wide spread accurate measurement of birth weight was not practicable, thus easily measurable substitutes for birth weight were therefore needed.

In the present study, an attempt has been made to find such substitute for birth weight and to establish a cut-off value for the detection of birth weight of $<2.5 \mathrm{~kg}$.

The present study was conducted on 500 newborns (286 male and 214 female). Mean birth weight of the study subjects was $2.58+0.676 \mathrm{~kg}$. This is similar to other studies done by Diamond I et al., $(2.798,2.634$ and 2.850 in New Delhi (A), New Delhi (B) and Chandigarh) and Huque F et al. in Bangladesh (2.679) $[6,7]$ but not in line with other studies done in Brazil (3.101), Egypt (3.5) and Nepal (3.029) [8,9,10].

At the cut-off value of $<2.5 \mathrm{~kg}$, the prevalence of LBW was $52.4 \%(\mathrm{n}=262)$ in the present study; which was a little higher when compared to other studies done in Bangladesh (15.18\%) and South India (38.2\%) [11,12] but it was comparable to the study done by Kaur $\mathrm{M}$ et al., (48.7\%) [13].

Comparison of anthropometric parameters of our study with other studies:

Thigh circumference: In the present study, among all the anthropometric measurements, high correlation was found with birth weight and thigh circumference $(\mathrm{r}-$ 0.776). Similar high correlation with thigh circumference was found in other studies done by JN Sharma et al., ( $r-0.9201)$ [14], Ahmed M ( $r-0.789$ in males and $r-0.804$ in females) [15], Ramji $S$ et al., (0.918) [16] and Oo WM (0.82)[17]
Calf circumference: The correlation between birth weight and calf circumference was found to be 0.646 , next to thigh circumference. But in other studies done by Neela $J$ et al., (0.83) [18], Samal GC et al., (0.78)[19], Das JC et al., (0.946)[20], correlation value was found to be high than the present study.

Mid Upper arm circumference: MUAC correlated with birth weight with the value of 0.635 in the present study. The values of correlation were found to be high in other studies done by Sharma JN et al., (0.8912) [14], Ramji S et al (0.8292) [16], Ahmed FU et al (0.7920) [21]. Bhargava SK et al (0.8110) [22], Das JC et al (0.9560) [20].

Head circumference: In the present study, the correlation between birth weight and head circumference was found to be 0.609 . Other studies reported correlation values of 0.71 [23], 0.7257[14], 0.7264 [22], 0.68 [18], 0.6200 [24].

Chest circumference: 0.581 was the correlation value found between birth weight and chest circumference. This value is in line with a study done by Neeluri $R$ ( 0.6090 [23] but lower compared to other studies where the correlation value is around $0.8[14,18,22]$.

Crown-Heel length: The correlation between CHL and birthweight in the present study was 0.492. Similar correlation value was found in the study done by Neeluri R (0.549) and Samal GC [0.57] but not in line with other studies -0.8081 [14], 0.8023 [22].

Foot length: Among all the anthropometric measurements, the correlation value was found to be low between birth weight and foot length $(r-0.460)$. This is in contrast to the results found in other studies done by Amar MT et al(r-0.715[25] and Gowri S et al(0.94) [26] 
Recommendation- We recommend use of a simple 'Tri-colored tape' for anthropometric measurements to facilitate early detection of LBW newborns especially for home deliveries in rural communities so as to provide timely management. The device should be flat, flexible, non-stretchable and suitably coloured in red, yellow and green, so that these can be used and understood easily by the illiterate Traditional Birth Attendants (TBA).

\section{Conclusion}

It can be concluded that all the anthropometric measurements correlate significantly with birth weight. In the present study, the highest correlation was found between birth weight and thigh circumference, followed by Calf circumference, MUAC, Head circumference, Chest circumference, Crown-Heel length and Foot length. Thus, anthropometric parameters can be considered as a useful tool to identify low birth-weight.

The results of this study suggest that thigh circumference is a simple and cheap method for detecting and screening low birth weight babies by using a non-stretchable measuring tape. Thigh circumference is measured at the most prominent position of the thigh. This can help relatives and grass root level workers to predict LBW babies in rural or hard to reach areas and aid in better care of the high-risk child. Addition to it, these measurements are simple, easy, cost - effective to be introduced in the current health care system.

\section{What is already known?}

The prevalence of Low birth weights babies is high in developing countries like India and appropriate alternative are needed in rural and hard to reach areas to predict birth weight for early management of the babies.

\section{Contributions}

- Dr Raghavendra Doddamani helped in data collection and analysis.

- Jyothi SD wrote first draft of the manuscript.

- Tejaswi Vittal Pujar made final correction of manuscript before submission.

- All authors approved submission of the manuscript and own responsibility of the manuscript.

- None of the authors have any conflict of interest.

Ethical approval: obtained

Funding: Nil, Conflict of interest: None initiated, Perission from IRB: Yes

\section{References}

1. Global Nutrition Targets 2025 Low BW Policy Brief. World Health Organisation. Available from http:// apps. who.int/iris/bitstream/handle/10665/149020/WHO_NM H_NHD_14.5_eng.pdf? sequence $=2$

2. Low birthweight, country, regional and global estimates, WHO and UNICEF. Available from http:// apps.who.int/iris/bitstream/handle/10665/43184/928063 8327.pdf;jsessionid $=35448 \mathrm{~F} 11 \mathrm{~B} 355 \mathrm{C} 7956 \mathrm{~A} 1111 \mathrm{CAA}$ B4F8CC4? sequence $=1$

3. Office of the Registrar General. Sample Registration System Statistical Report 2011. New Delhi: Ministry of Home Affairs, Government of India; 2013 Sep. Available at: http://censusindia.gov.in /vitalstatistics/ SRS_Bulletins/SRS_Bulletins

4. SRS Bulletin, Sample registration system registrar general, India. Volume 51 No.1, September,2017. Available from http://censusindia.gov.in/vital_statistics / SRS_Bulletins/ SRS\% 20 Bulletin\% 20-Sep_2017Rate-2016.pdf

5. Ballard JL, Khoury JC, Wedig K, et al. New Ballard Score, expanded to include extremely premature infants . J Pediatr. 1991 Sep;119(3):417-23.

6. Use of a simple anthropometric measurement to predict birth weight. WHO Collaborative Study of Birth Weight Surrogates. Bull World Health Organ. 1993; 71(2):157-63.

7. Huque F and Hussain ZAM. Detection of low birth weight newborn babies by anthropometric measurements in Bangladesh. Indian Journal of Paediatrics 1991;58(2):223-31.

8. Alves JGB, Lima GM, AzeVedo GN, Cabral VB, Moggi RS, Nunes R. Evaluation of newborn arm circumference as an indicator of low birth weight. Bulletin of Pan American Health Organisation 1991;25 (3):207-9.

9. Hossain MM, Habib M, DuPont HL. Association between birth weight and birth arm circumference of neonates in rural Egypt. Indian J Pediatr. 1994 Jan-Feb; 61(1):81-7.

10. Sreeramareddy CT, Chuni N, Patil R, et al. Anthropometric surrogates to identify low birth weight Nepalese newborns: a hospital-basedstudy. DOI:10. 1186/1471-2431-8-16 


\section{Original Research Article}

11. Dhar B, Mowlah G, Nahar S, Islam N. Birth-weight status of newborns and its relationship with other anthropometric parameters in apublic maternity hospital in Dhaka, Bangladesh. J Health Popul Nutr. 2002 Mar; 20 (1):36-41.

12. Suneetha B, Kavitha VK. A Study of Relationship between Birthweight and Various Anthropometric Parameters in Neonates. IOSR Journal of Dental and Medical Sciences. 2011Vol.3, No.12, 752-756.

13.Das JC, Khanam ST. Correlation of anthropometric measurements of mothers and their newborns. Bangladesh Med Res Counc Bull. 1997 Apr;23(1): 10-5.

14. Sharma JN, Saxena S, Sharma U. Thigh circumference at birth as the best predictor of low birth weight babies. Indian Pediatr. 1989 Jan;26(1):18-21.

15. Ahmed M, Colaco SM, Ali MA, Ahmed Z. Birth Weight Status of Newborn and Its Relationship With Other Anthropometric Parameters. Int J Med Health Sci. Jan 2014,Vol-3;Issue-1, p 1-6

16. Ramji S, Marwah J, Satyanarayana L, et al. Neonatal thigh circumference asan alternative indicator of low birth weight. Indian J Med Res. 1986 Jun; 83: 653-4.

17. Oo WM, Moe H. Predictive Model of Birth Weight Using Simple Anthropometric Measurements of Baby and Selected Maternal Characteristics. The Myanmar Health Sciences Research Journal, 2015, Vol 27, No 1, p 1-9

18. Neela J, Raman L, Balakrishna N, Rao KV. Usefulness of calf circumference as a measure for screening low birth weight infants. Indian Pediatr. 1991 Aug;28(8):881-4.
19. Samal GC, Swain AK. Calf circumference as an alternative to birth weight for identification of low birth weight babies. Indian Pediatr. 2001 Mar;38(3):275-7.

20. Das JC, Afroze A, Khanam ST, Paul N. Mid-arm circumference: an alternative measure for screening low birth weight babies. Bangladesh Med Res Counc Bull. 2005 Apr;31(1):1-6.

21. Ahmed FU, Karim E, Bhuiyan SN. Mid-arm circumference at birth as predictor of low birth weight and neonatal mortality. J Biosoc Sci. 2000 Oct;32(4): 487-93.

22. Bhargava SK, Ramji S, Kumar A, et al. Midarm and chest circumferences at birth as predictors of low birth weight and neonatal mortality in the community. Br Med J (Clin Res Ed). 1985 Dec 7;291 (6509):1617-9.

23. Rajesh N, Kiran P. Identification of an anthropometric surrogate to low birth weight in newborns: a hospital based cross sectional study. Int J Community Med Public Health 2018;5:2066-71

24. Samal GC, Swain AK. Calf circumference as an alternative to birth weight for identification of low birth weight babies. Indian Pediatr. 2001 Mar;38(3): 275-7.

25. Amar MT, Rewat M, Amol L. Neonatal Foot Length: An Alternative Predictor of Low Birth Weight Babies in Rural India. Acad J Ped Neonatol. 2016;1 (4):555569

26. Gowri S, Kumar GV. Clinical study of the correlation of foot length and birth weight among newborns in a tertiary care hospital. Int $\mathrm{J}$ Contemp Pediatr 2017;4:979-83.

\section{How to cite this article?}

Doddamani R, Jyothi S.D, Pujar T.V. Interpretation of low birth weight babies by anthropometric measurements in South India. Int J Pediatr Res.2018;5(7): 368-374.doi:10.17511/ijpr.2018.i07.05. 